International Journal of Biological Sciences

ISSN 1449-2288 www.biolsci.org 2006 2:17-22

Research paper

C2006 Ivyspring International Publisher. All rights reserved

\title{
The effects of sympathectomy and dexamethasone in rats ingesting sucrose
}

\author{
Margarita Franco-Colín, Iván Villanueva, Manuel Piñón and Radu Racotta
}

Departamento de Fisiología, Escuela Nacional de Ciencias Biológicas, Instituto Politécnico Nacional (IPN), México Distrito Federal, Mexico.

Corresponding address: Radu Racotta, PhD, Departamento de Fisiología, ENCB, Prol. De Carpio y Plan de Ayala, México D.F. 11340, Mexico. Phone: 52(55)57296300/62348; e-mail: rracotta@ipn.mx

Received: 2006.02.01; Accepted: 2006.03.04; Published: 2006.03.04

Both high-sucrose diet and dexamethasone (D) treatment increase plasma insulin and glucose levels and induce insulin resistance. We showed in a previous work (Franco-Colin, et al. Metabolism 2000; 49:1289-1294) that combining both protocols for 7 weeks induced less body weight gain in treated rats without affecting mean daily food intake. Since such an effect may be explained by an increase in caloric expenditure, possibly due to activation of the sympathetic nervous system by sucrose ingestion, in this work, and using $10 \%$ sucrose in the drinking water, male Wistar rats were divided into 4 groups. Two groups were sympathectomized using guanethidine $(\mathrm{Gu})$ treatment for 3 weeks. One of these groups of rats received D in the drinking water. Of the 2 groups not receiving $\mathrm{Gu}$, one was the control (C) and the other received D. After 8 weeks a glucose tolerance test was done. The rats were sacrificed and liver triglyceride (TG), perifemoral muscle lipid, and norepinephrine (NE) levels in the liver spleen, pancreas, and heart were determined. Gu-treated rats (Gu and Gu+D groups) showed less than 10\% NE concentration compared to C and D rats, less daily caloric intake and body-weight gain, more sucrose intake, and better glucose tolerance. The area under the curve after glucose administration correlated significantly with the mean body weight gain of the rats, except for D group. Groups D (D and Gu+D) also showed less caloric intake and body-weight gain but higher liver weight and TG concentration and lower peripheral muscle mass. The combination of $\mathrm{Gu}+\mathrm{D}$ treatments showed some peculiar results: negative body weight gain, a fatty liver, and low muscle mass. Though the glucose tolerance test had the worst results for the D group, it showed the best results in the Gu+D group. There were significant interactions for Guan X Dex by twoway ANOVA test for the area under the curve in the glucose tolerance test, muscle mass, and muscle lipids. The results suggest that dexamethasone catabolic effect is not caused by sympathetic activation.

Key words: Guanethidine sympathectomy, dexamethasone, high-sucrose diet.

\section{INTRODUCTION}

Weight gain or loss in otherwise healthy humans and animals is because of an imbalance between caloric intake and caloric expenditure. The first term is represented by the quantity of macronutrients ingested during a time interval (days, weeks, etc) taking into account that each macronutrient has a specific caloric value. Caloric expenditure is more difficult to estimate and is usually measured using indirect calorimetry.

Glucocorticoids are involved in the control of energy metabolism and body weight. Long-term administration of dexamethasone (D) in low doses in the drinking water of rats $(3-4 \mu \mathrm{g} /$ day $)$ reduced weight gain without affecting food intake, suggesting an increase in caloric expenditure [1,2].

Feeding a sucrose diet induces some effects similar to those of D administration, such as the increase in insulin levels and resistance $[3,4]$ and in plasma glucose levels [5]. The common mechanism of the action of glucose and D on glucose metabolism seems to be the sensitization of pancreatic $\beta$-cells to glucose-induced insulin secretion [6,7]. In a previous work when we used both $\mathrm{D}$ treatment and high- sucrose diet in rats, the stronger effect on fat accumulation relative to body weight was seen only after the combination of both treatments [2].

Another factor clearly involved in the control of metabolism and energy balance is the activity of the sympathoadrenal system. Both epinephrine (E) and norepinephrine (NE) are assumed to be implicated in the control of feeding [8] and of body weight [9], along with their well-known effect on plasma glucose and free fatty acid levels that results from their actions on the hepatic and adipose tissue. In spite of the important role played by the sympathetic nervous system in the cardiovascular, renal, respiratory, and metabolic functions, chronic sympathectomy, induced experimentally by guanethidine $(\mathrm{Gu})$ treatment [10], produces only small alterations when administered either to neonatal or adult rats. Gu treatment has been reported to have no effect on body weight [11] or just to lower it slightly $[12,13]$. Caloric intake is slightly reduced $[11,14]$. Recently we showed that neonatal rats treated with $\mathrm{Gu}$ show, as adults, a higher hypophagic response to intraperitoneal catecholamine administration, a lower resting oxygen consumption, and a higher respiratory quotient at rest, suggesting a lower rate of lipid use [15]. While 
both high-sucrose diet and D administration induces similar changes in glucose and lipid metabolism, the experimental manipulation of these two factors has opposite effects on the sympathetic nervous system activity: sucrose ingestion stimulates it [16] whereas D has been reported to suppress it [17].

Because of our interest in the metabolic effects of sympathectomy [15] the aim of the present work was to assess in adult rats the effects of $\mathrm{D}$ on a background of a high-sucrose diet, on food intake, body weight, glucose tolerance, and lipid accumulation in the liver and muscle in rats treated with $\mathrm{Gu}$. It was hypothesized that the poor food efficiency shown by D-treated rats [1,2] might be caused by an increase in energy expenditure perhaps due to an increase in sympathetic activity.

\section{MATERIAL AND METHODS}

\section{Animals and diet}

Twenty-eight male Wistar rats $(377 \pm 7$ g; $6-8$ months old) were housed in individual cages in a temperature-controlled room $\left(23^{\circ} \pm 1^{\circ} \mathrm{C}\right)$ with a $12 \mathrm{~h}$ light/12 h dark cycle. Powdered Rodent Lab Chow 5001 and $10 \%$ sucrose in tap water were available ad libitum. At the start of the experiment, the rats were divided into 4 groups, each having 7 rats of similar mean body weight.

\section{Treatments}

After one week, 2 groups of rats received guanethidine (Guanethidine monosulfate, Sigma Chem., St Louis, MO) $50 \mathrm{mg} / \mathrm{kg}$ intraperitoneally (ip) three times a week for 3 weeks. After two weeks of guanethidine $(\mathrm{Gu})$ treatment, 2 groups of animals, one having received $\mathrm{Gu}$ and another without $\mathrm{Gu}$, started to drink water containing, beside sucrose, dexamethasone (Decadron, Lab. Merck Sharp \& Dohme, Mexico) in doses calculated, according to the water intake of each treated rat, to represent approximately $2.2 \mu \mathrm{g}$ dexamethasone (D) per rat per day. Oral D administration was continued until rats were sacrificed. This yielded 4 experimental groups: control $(\mathrm{C})$, guanethidine $(\mathrm{Gu})$, dexamethasone $(\mathrm{D})$, and $\mathrm{Gu}+\mathrm{D}$.

\section{Measurements}

Food and water intake were measured daily and body weight weekly for 7 weeks, one week before the start of the Gu treatment, the 3 weeks of Gu treatment and the 4 weeks of $\mathrm{D}$ treatment, with one week overlap of the two treatments. Water intake measurements allowed the determination of sugar intake. Total caloric intake expressed as $\mathrm{kJ} /$ day was calculated by summing the sucrose ingestion (estimated to be $4 \mathrm{Cal}=16.74 \mathrm{~kJ}$ ) and the chow intake $(3.96 \mathrm{Cal}=16.57 \mathrm{~kJ})$. After these 56 days, and continuing $\mathrm{D}$ oral administration, glucose tolerance was determined in the rats that had fasted overnight. Blood was obtained from the tail tip and whole-blood glucose concentrations were measured using an enzymatic kit (Farmaceuticos Lakeside, Mexico) before and 30,60, and $120 \mathrm{~min}$ after ip injection of 3.6 $\mathrm{g} / \mathrm{kg}(20 \mathrm{mmol} / \mathrm{kg})$ of glucose. Finally, 7 to 10 days later and after an overnight fast the rats were anesthetized with $60 \mathrm{mg} / \mathrm{kg}$ sodium pentobarbital (Anestesal, SmithKline Beecham, Farmaceutica, Mexico), their abdomens were opened, their liver was removed and weighed, and then frozen for further triglyceride determinations. A sample of liver, pancreas, spleen, and heart ventricle was also immediately removed, homogenized in ice-cold $0.4 \mathrm{~N}$ perchloric acid, centrifuged, and kept at $-20^{\circ} \mathrm{C}$ for catecholamine analysis. The perifemoral muscles of one leg were also dissected and frozen for further lipid determinations. Liver triglycerides were determined using a kit from Sigma Chem., St. Louis, MO. The total lipids in dried samples of muscle were obtained by extraction in a Soxhlet Extractor (Kimax, Mexico) with petroleum ether. Catecholamines were extracted, after thawing of tissue samples, by adsorption on acid-washed alumina in Tris buffer $(\mathrm{pH}$ 8.6) containing EDTA, washed with deionized water several times, and eluted in $200 \mu \mathrm{L} 0.1 \mathrm{~N}$ perchloric acid. Norepinephrine (NE) and epinephrine (E) concentrations were measured using high-performance liquid chromatography with electrochemical detection (ESA Coulochem II; Bedford, MA) by using a degassed mobile phase in an isocratic $0.6 \mathrm{~mL} / \mathrm{min}$ flow, with 3,4dihydroxybenzylamine added as an internal standard $[15,18]$.

Statistics

The data were analyzed by two-way (Guanethidine X Dexamethasone) and one-way analysis of variance (ANOVA). Results are expressed as mean \pm SEM. Linear regression was calculated between the glycemia AUC and the mean daily body weight gain. The level of significance was set at $P<$ 0.05 .

\section{RESULTS}

Norepinephrine levels were drastically reduced by $\mathrm{Gu}$ treatment in the 4 organs (Table 1 ).

Table 1. Norepinephrine levels (ng/g) in liver, spleen, pancreas, and heart in the four groups of rats

\begin{tabular}{|c|c|c|c|c|}
\hline Treatments/organ & Liver & Spleen & Pancreas & Heart \\
\hline Control & $48.3 \pm 3.5^{\mathrm{a}}$ & $1001.0 \pm 165.8^{\mathrm{a}}$ & $440.5 \pm 114.4^{\mathrm{a}}$ & $430.9 \pm 53.1^{\mathrm{a}}$ \\
\hline Guanethidine & $3.9 \pm 1.1^{\mathrm{b}}$ & $7.2 \pm 1.9^{\mathrm{b}}$ & $45.8 \pm 24.6^{\mathrm{b}}$ & $12.2 \pm 2.8^{\mathrm{b}}$ \\
\hline $\begin{array}{c}\text { Dexamethasone } \\
57.5 \pm 6.6^{\mathrm{a}}\end{array}$ & $880.6 \pm 144.0^{\mathrm{a}}$ & $586.3 \pm 54.1^{\mathrm{a}}$ & $649.7 \pm 124.4^{\mathrm{a}}$ \\
\hline Guan+Dex & $4.2 \pm 1.3^{\mathrm{b}}$ & $28.4 \pm 15.3^{\mathrm{b}}$ & $16.0 \pm 6.0^{\mathrm{b}}$ & $20.0 \pm 11.0^{\mathrm{b}}$ \\
\hline $\begin{array}{c}\text { ANOVA(F) } \\
\text { Guanethidine }\end{array}$ & $12^{* *}$ & $67^{* *}$ & $74^{* *}$ & $38^{* *}$ \\
\hline $\begin{array}{c}{ }^{* *} P<0.01 \text { by two-way ANOVA. Within a column, values bearing the } \\
\text { same letter are not significantly different by one-way ANOVA. }\end{array}$
\end{tabular}

Epinephrine levels in the unsympathectomized groups of rats were much lower than those of NE and Gu reduced them only in the heart: $5.7 \pm 1 \mathrm{ng} / \mathrm{g}$ vs 9.7 $\pm 1.2 \mathrm{ng} / \mathrm{g}(\mathrm{F}=7.5, P<0.02)$. Dexamethasone 
treatment did not affect catecholamine concentrations.

Total caloric intake (kJ/day), percentage of sucrose intake, and body weight gain ( $\mathrm{g} /$ day) were calculated for 7 weeks for the control group (C), 6 weeks for the $\mathrm{Gu}$-treated rats (groups $\mathrm{Gu}$ and $\mathrm{Gu}+\mathrm{D}$ ) and 4 weeks for the group that received only dexamethasone (group D). Table 2 shows less food intake for the three treated groups, without significant differences among them. Relative sucrose intake was higher in $\mathrm{Gu}+\mathrm{D}$ rats. Body-weight gain was much more affected in both groups receiving $D$ treatment. All three variables were affected more by the combination of sympathectomy with $\mathrm{D}$ treatment.

Table 2. Total caloric intake, percentage of sucrose intake, and body weight gain in the four groups of rats.

\begin{tabular}{|c|c|c|c|}
\hline Treatments & $\begin{array}{c}\text { Total caloric } \\
\text { intake } \\
\text { (kJ/day) }\end{array}$ & $\begin{array}{c}\text { Sucrose } \\
\text { caloric } \\
\text { intake (\%) }\end{array}$ & $\begin{array}{c}\text { Body weight } \\
\text { gain } \\
\text { g/day }\end{array}$ \\
\hline Control & $446.0 \pm 14.4^{\mathrm{a}}$ & $48.0 \pm 1.3^{\mathrm{a}}$ & $1.26 \pm 0.16^{\mathrm{a}}$ \\
\hline Guanethidine & $390.8 \pm 9.5^{\mathrm{b}}$ & $51.6 \pm 2.6^{\mathrm{ab}}$ & $0.87 \pm 0.15^{\mathrm{a}}$ \\
\hline Dexametasone & $404.2 \pm 13.7^{\mathrm{b}}$ & $50.7 \pm 1.4^{\mathrm{a}}$ & $0.20 \pm 0.13^{\mathrm{b}}$ \\
\hline Guan + Dex & $370.3 \pm 17.6^{\mathrm{b}}$ & $56.8 \pm 1.4^{\mathrm{b}}$ & $-0.37 \pm 0.22^{\mathrm{b}}$ \\
\hline ANOVA (F) & & & \\
\hline Guanethidine & $15.8^{* *}$ & $7.5^{*}$ & $12.3^{* *}$ \\
\hline Dexamethasone & $7.7^{* *}$ & $4.8^{*}$ & $70.8^{* *}$ \\
\hline Guan X Dex & 0.9 & 0.5 & 0.5 \\
\hline
\end{tabular}

$* P<0.05 ;{ }^{* *} P<0.01$ by two-way ANOVA. Within a column, values bearing the same letter are not significantly different by one-way ANOVA.

Figure 1 shows the evolution of blood glucose after $3.6 \mathrm{mg} / \mathrm{kg}$ glucose ip. Glucose tolerance was significantly improved in the sympathectomized groups and the D group showed the worst tolerance.
Excepting the $\mathrm{D}$ group, there is a significant correlation $(P<0.02)$ between glucose AUC after glucose administration and body-weight gain (Fig. 2).

Table 3 shows the relative liver weight, the relative content of triglycerides in the liver and lipids in the perifemoral muscles, and the wet weight of the muscle. Relative liver weight and liver triglycerides were significantly higher in both groups of D-treated rats, whereas lipids in muscle were higher only in the $\mathrm{Gu}+\mathrm{D}$ group. The significant interaction between $\mathrm{Gu}$ and $\mathrm{D}$ treatment in this case shows that only their combination increased muscle lipids under these particular conditions. Similar differences between groups are shown by the perifemoral muscle mass.

Figure 1. Evolution of whole-blood glucose before and after the intraperitoneal administration of $3.6 \mathrm{~g}$ glucose per $\mathrm{kg}$ in control (C), dexamethasone (D)-, guanethidine (Gu)-, and guanethidine plus dexamethasone $(\mathrm{Gu}+\mathrm{D})$-treated rats. Two-way ANOVA results for Area Under the Curve (AUC) are inserted. Values bearing the same letter for the glycemic level at each time interval and for AUC values (mean glycemia in $120 \mathrm{~min}$ ) are not significantly different by one-way ANOVA.

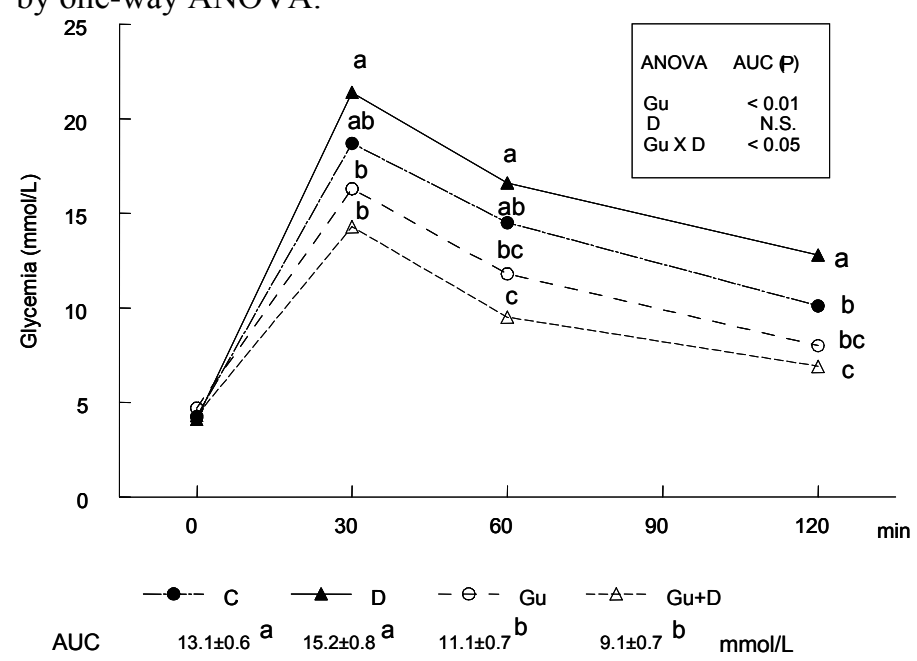

Figure. 2. Individual correlation for glycemia AUC and daily body weight gain. (-) Linear regression for all rats $(\mathrm{r}=0.29$, not significant; (---) Linear regression without $\mathrm{D}$ group $(\mathrm{r}=0.64, P<0.02)$.

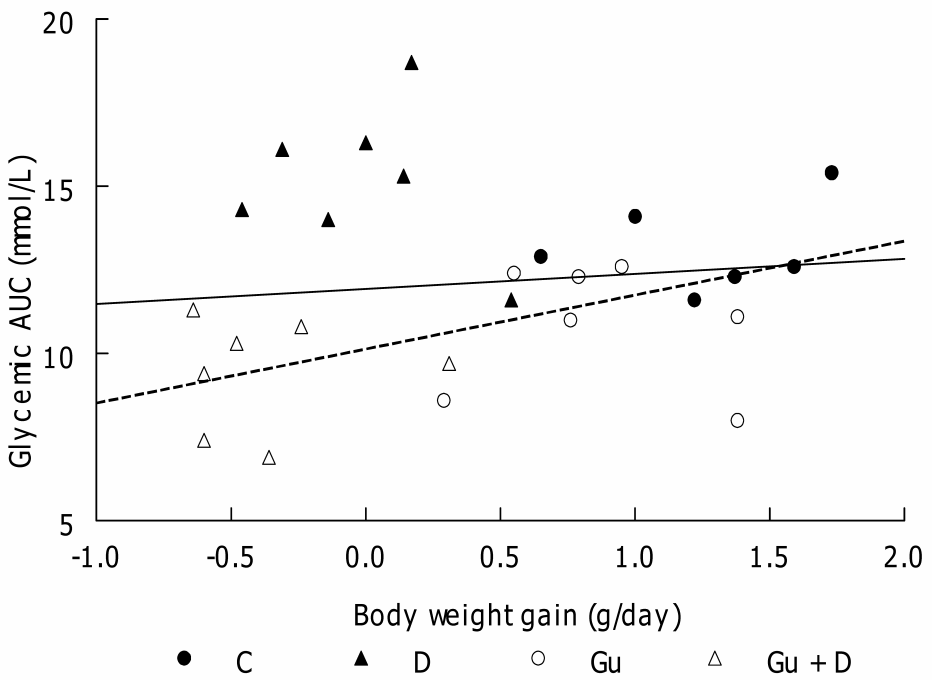


Table 3. Relative weight and triglyceride content of liver, relative lipid content in perifemoral muscles, and muscle mass in the four groups of rats

\begin{tabular}{|c|c|c|c|c|}
\hline Treatment & Liver/body weight (\%) & Liver triglyceride $(\mathrm{mmol} / \mathrm{kg})$ & Muscle lipids (\% wet weight) & Muscle mass (g) \\
\hline Guanethidine & $3.20 \pm 0.13^{\mathrm{ab}}$ & $19.9 \pm 1.7^{a}$ & $2.03 \pm 0.14^{a}$ & $8.0 \pm 0.4^{\mathrm{a}}$ \\
\hline Guan + Dex & $3.72 \pm 0.22^{b}$ & $33.5 \pm 2.9^{b}$ & $3.32 \pm 0.44^{b}$ & $6.2 \pm 0.4^{b}$ \\
\hline ANOVA $(F)$ & & & & \\
\hline Guan X Dex & 0.8 & 0.3 & $8.8^{* *}$ & $4.6^{*}$ \\
\hline
\end{tabular}

${ }^{*} P<0.05 ;{ }^{* *} P<0.01$ by two-way ANOVA. Within a column, values bearing the same letter are not significantly different by one-way ANOVA.

\section{DISCUSSION}

Guanethidine administration in adult rats three times per week for three weeks resulted in low NE concentration in four internal organs (Table 1), as measured more than two months after having concluded the treatment, confirming that this protocol is as effective as the neonatal administration [19]. The effects in heart and liver were similar to those obtained in a previous experiment in which $\mathrm{Gu}$ was injected into neonatal rats [15].

Sympathectomy alone had weak effects on food intake and body-weight gain (Table 2), confirming the results of other authors [11-14]. The Gu group of rats showed better glucose tolerance. Glucose tolerance depends on peripheral insulin resistance, hepatic insulin resistance, and/or glucose-induced pancreatic insulin secretion. Sympathetic activation stimulates peripheral glucose uptake by a $\beta_{3}$-adrenergic effect [20-22] but inhibits insulin secretion, an $\mathrm{a}_{2}$-adrenergic effect [22]. Insulin was not measured in this work but the better glucose tolerance of the sympathectomized rats might be attributed to the practical lack of NE in the pancreas, which should permit the release of more insulin under the stimulus of glucose.

Chronic sucrose intake induces chronic hyperinsulinemia [24-26]. This results in a stimulation of leptin secretion, $[26,27]$ more so in the presence of low sympathetic activity, because $\beta_{3}$-adrenergic action inhibits leptin secretion $[26,28,29]$. Compared with the situation of the control group, sympathectomy may have increased leptin production resulting in improved glucose uptake and lower body-weight gain $[30,31]$. A relationship between these variables is shown by their significant linear correlation when the D group was not included (see below).

Generally speaking, dexamethasone was administered by various authors in much larger doses and for less time. Coderre et al. [24] combined sucrose in the drinking water with subcutaneous injection of $\mathrm{D}$ (0.4 or $1.0 \mathrm{mg} /$ day) for 7 days. The $\mathrm{D}$ treatment with the lower dose induced body-weight loss, hyperglycemia, hyperinsulinemia and hypertriglyceridemia. Sucrose affected only the two last variables, and the combination of treatments did not increase the effects of these large doses of $\mathrm{D}$.

In the present work, glucose tolerance of the $\mathrm{D}$ group was the worst and may be easily attributed to
D-induced insulin resistance [3]. The relationship between glycemic AUC and body-weight gain was different from the other three groups and, although not reaching statistical significance because of the data of one rat (see Fig. 2), the slope of the linear regression for the other six rats is much steeper, suggesting that glycemic AUC increased much more for each increase in body weight gain. This shows that D-induced insulin resistance is increased proportionally more when body weight increases.

Some interesting results were shown by the $\mathrm{Gu}+\mathrm{D}$ group of rats. The huge reduction of $\mathrm{NE}$ content induced by sympathectomy in the 4 organs was not affected by D administration but food intake was significantly lower and body-weight actually decreased showing the catabolic action of $\mathrm{D}$ is probably not due to sympathetic activation. The proportional intake of sucrose was significantly higher in this group. The differences between these variables in $\mathrm{D}$ and $\mathrm{Gu}+\mathrm{D}$ are caused, perhaps directly, by the low sympathetic activity in the second group. As already discussed, sympathectomy may increase leptin production and it is known that glucocorticoids stimulate it $[32,33]$. The difference between the two groups could be that, in the D group, the inhibitory action of the sympathetic system on leptin secretion is present but is lacking in the $\mathrm{Gu}+\mathrm{D}$ group.

High leptin levels could tentatively explain also the preference for sucrose by these rats. Beck et al. [34] reported that ghrelin, which stimulates feeding, is inversely correlated with plasma leptin and has lower plasma levels in the carbohydrate-preferring rats. This suggests indirectly that, on the contrary, high leptin levels may be associated with carbohydrate preference. Another indirect clue is given by the article of Velasquez-Mieyer et al. [35] reporting that the suppression of insulin secretion in obese humans induced, among other effects, a decrease in leptin levels and in carbohydrate craving.

The same $\mathrm{Gu}+\mathrm{D}$ group of rats showed the best glucose tolerance. Because this was the group that had lost weight and had supposedly also the highest leptin levels, two conditions that improve glucose tolerance $[29,30]$ such a result might be expected. The statistically significant correlation between bodyweight gain and glucose AUC support this interpretation. 
The D-induced increase in relative liver weight and liver triglyceride content confirms our previous results [2]. Muscle lipids are associated with insulin resistance [36,37]. However, the present results show that the group $\mathrm{Gu}+\mathrm{D}$ had the best glucose tolerance but the highest lipid content in the perifemoral muscles, clearly caused by the combination of the two treatments, as shown by the significant interaction between their effects. The relatively higher levels of fat might be caused by the relatively low level of the main component of muscle, the proteins, as shown by the low muscle mass in the $\mathrm{Gu}+\mathrm{D}$ group. The proteolytic action of glucocorticoids is well-known and, as the catecholamines inhibit proteolysis [38], this muscle mass reduction could be caused by a potentiation of effects of the two treatments.

In summary, in adult rats drinking a 10\% sucrose solution chemical sympathectomy caused by guanethidine treatment for 3 weeks reduced norepinephrine levels in four organs by more than $90 \%$ and decreased food intake. It also improved glucose tolerance, a result that has not been reported before. Dexamethasone, besides reducing food intake and body-weight gain and increasing liver triglyceride content, impaired glucose tolerance. When guanethidine-treated animals received dexamethasone some novel aspects were seen: an increase in drinking the sucrose solution, a negative body-weight gain, and a consistently better glucose tolerance. This last effect was the only improvement shown by combining sympathectomy with dexamethasone treatment. In exchange, the negative food efficiency suggests that dexamethasone catabolic effect is not due to sympathetic activation.

\section{Acknowledgements}

This work was supported in part by Project Grant No. 990169 from Coordinación General de Posgrado e Investigación-IPN. R.R. is a fellow of Comisión de Operación y Fomento de Actividades Académicas-IPN. The authors thank Dr Ellis Glazier for editing the English-language text.

\section{Conflict of interest}

The authors have declared that no conflict of interest exists.

\section{REFERENCES}

1. Palacios E, Piñon-López MJ, Racotta IS, Racotta R. Effect of lipectomy and long-term dexamethasone on visceral fat and metabolic variables in rats. Metabolism 1995; 44:1631-1638.

2. Franco-Colin M, Tellez-Lopez AM, Quevedo-Corona L, Racotta R. Effects of long-term high-sucrose and dexamethasone on fat depots, liver fat, and lipid fuel fluxes through the retroperitoneal adipose tissue and splanchnic area in rats. Metabolism 2000; 49:1289-1294.

3. Stojanovska L, Rosella G, Proietto J. Evolution of dexamethasone-induced insulin resistance in rats. Am J Physiol 1990, 258:E748-E756.
4. Severino C, Brizzi P, Solinas A, Secchi G, Maiolo M, Tonolo G. Low-dose dexamethasone in the rat: a model to study insulin resistance. Am J Physiol Endocrinol Metab 2002; 283:E367-E373.

5. Dimitriadis G, Leighton B, Parry-Billings $M$, Sasson S, Young M, Krause U, Bevan S, Piva T, Wegener G, Newsholme EA. Effects of glucocorticoid excess on the sensitivity of glucose transport and metabolism to insulin in rat skeletal muscle. Biochem J 1997; 321:707-712.

6. Oda N, Nakai A, Mokuno T, Sawai I, Nishida Y, Mano T, Asano K, Itoh Y, Kotake M, Kato S. Dexamethasone-induced changes in glucose transporter 4 in rat heart muscle, skeletal muscle and adipocytes. Eur J Endocrinol 1995; 133:121-126.

7. Karlsson S, Östlund B, Myrsen-Axcrona U, Sundler F, Ahren B. Beta-cell adaptation to dexamethasone-induced insulin resistance in rats involves increased glucose responsiveness but not glucose effectiveness. Pancreas 2001; 22:148-156.

8. Russek M, Vega C, Barrera J, Soto-Mora LM, Lanzagorta A, Racotta R. Anorexia elicited by different catecholamines in rats. Appetite 1987; 9:119-126.

9. Bray GA. Obesity, a disorder of nutrient partitioning: the MONA LISA hypothesis. J Nutr 1991; 121:1146-1162.

10. Picklo MJ. Methods of sympathetic degeneration and alteration. J Auton Nerv Syst 1997; 62:111-125,

11. Levin BE, Triscari J, Marquet E, Sullivan AC. Dietary obesity and neonatal sympathectomy. I. Effects on body composition and brown adipose. Am J Physiol 1984; 247:R979-R987.

12. Storlien LH, Bellingham WP, Smythe GA. Effect of guanethidine sympathectomy on intake and body weight of intact and LHA-lesioned rats. Physiol Behav 1983; 31:401-404.

13. Tordoff MG, Vanderweele DA, Katz TJ, Chene WS, Novin D. Meal patterns and glucoprivic feeding in the guanethidinesympathectomized, adrenodemedullated rat. Physiol Behav 1984; 32:229-235.

14. Tordoff MG. Influence of sympathectomy on body weight of rats given chow or supermarket diets. Physiol Behav 35:455460, 1985

15. Villanueva I, Piñon M, Quevedo-Corona L, Martínez-Olivares R, Racotta R. Chemical sympathectomy alters food intake and thermogenic responses to catecholamines in rats. Life Sci 2002; 71:789-801.

16. Young JB, Landsberg L. Stimulation of the sympathetic nervous system during sucrose feeding. Nature 1977; 269:615617.

17. Brown MR, Fisher LA. Glucocorticoid suppression of the sympathetic nervous system and adrenal medulla. Life Sci 1986; 39:1003-1012.

18. Eriksson BM, Persson BA. Determination of catecholamines in rat heart tissue and plasma samples by liquid chromatography with electrochemical detection. J Chromatogr 1982; 228:143-154.

19. Johnson EM Jr, O'Brien F. Evolution of the permanent sympathectomy produced by the administration of guanethidine in adult rats. J Pharmacol Exp Ther 1976; 196:5361.

20. Haque MS, Minokoshi Y, Hamai M, Iwai M, Horiuchi M, Shimazu T. Role of the sympathetic nervous system and insulin in enhancing glucose uptake in peripheral tissues after 
intrahypothalamic injection of leptin in rats. Diabetes 1999; 48:1706-1712.

21. Nonogaki K. New insights into sympathetic regulation of glucose and fat metabolism. Diabetologia 2000; 43:533-549.

22. Östenson CG, Cattaneo AG, Doxey JC, efenndic S. aAdrenoceptors and insulin release from pancreatic islets of normal and diabetic rats. Am J Physiol 1989; 257:E439-E443.

23. Kizhner T, Werman MJ. Long-term fructose intake: biochemical consequences and altered renal histology in the male rat. Metabolism 2002; 51:1538-1547.

24. Coderre L, Vallega GA, Pilch PF, Chipkin SR. In vivo effects of dexamethasone and sucrose on glucose transport (GLUT-4) protein tissue distribution. Am J Physiol 1996; 271:E643-E648.

25. Kim J-Y, Nolte LA, Hansen PA, Han DH, Kawanaka K, Holloszy JO. Insulin resistance of muscle glucose transport in male and female rats fed a high-sucrose diet. Am J Physiol 1999; 276:R665-R672.

26. Gettys TW, Harkness PJ, Watson PM. The $\beta_{3}$-adrenergic receptor inhibits insulin-stimulated leptin secretion from isolated rat adipocytes. Endocrinology 1996; 137:4054-4057.

27. Rayner DV, Trayhurn P. Regulation of leptin production: sympathetic nervous system interactions. J Mol Med 2001; 79:820.

28. Giacobino JP. Role of the $\beta_{3}$-adrenoceptor in the control of leptin expression. Horm Metab Res 1996; 28:633-637.

29. Sivitz WI, Fink BD, Morgan DA, Fox JM, Donohue PA, Haynes WG. Sympathetic inhibition, leptin, and uncoupling protein subtype expression in normal fasting rats. Am J Physiol 1999; 277:E668-E677.

30. Chinookoswong N, Wang JL, Shi ZQ. Leptin restores euglycemia and normalizes glucose turnover in insulindeficient diabetes in the rat. Diabetes 1999; 48:1487-1492.

31. Yaspelkis BB III, Ansary L, Ramey EL, Holland GJ, Loy SF. Chronic leptin administration increases insulin-stimulated skeletal muscle glucose uptake and transport. Metabolism 1999; 48:671-676.

32. Larsson H, Ahrën B. Short-term dexamethasone treatment increases plasma leptin independently of changes in insulin sensitivity. J Clin Endocrinol Metab 1996; 81:4428-4432.

33. Remesar X, Rafecas I, Fernández-López JA, Alemany M. Is leptin an insulin contra-regulatory hormone? FEBS Lett 1997; 402:9-11.

34. Beck B, Musse N, Stricker-Krongard A. Ghrelin, macronutrient intake and dietary preferences in long evans rats. Biochem Biophys Res Commun 2002; 292:1031-1035.

35. Velasquez-Mieyer PA, Cowan PA, Arheart KL, Buffington CK, Spencer KA, Connelly BE, Cowan GW, Lustig RH. Suppression of insulin secretion is associated with weight loss and altered macronutrient intake and preference in a subset of obese adults. Int J Obes Relat Metab Disord 2003; 27:219-226.

36. Dobbins RL, Szczepaniak LS, Bentley B, Esser V, Myhill J, McGarry JD. Prolonged inhibition of muscle carnitine palmytoiltransferase-1 promotes intramyocellular lipid accumulation and insulin resistance in rats. Diabetes 2001; 50:123-130.
37. Kelley DE. Skeletal muscle triglycerides: An aspect of regional adiposity and insulin resistance. Ann NY Acad Sci 2002; 967:135-145.

38. Navegantes LC, Resano NM, Migliorini RH, Kettelhut IC. Role of adrenoceptors and cAMP on the catecholamine-induced inhibition of proteolysis in rat skeletal muscle. Am J Physiol Endocrinol Metab 2000; 279:E663-E668. 